\title{
Experimental approach for assessing filter-cake removability derived from reservoir drill-in fluids
}

\author{
Asad Elmgerbi $^{1}$ (1) $\cdot$ Gerhard Thonhauser $^{1} \cdot$ Alexander Fine $^{1} \cdot$ Rafael E. Hincapie $^{2} \cdot$ Ante Borovina $^{2}$
}

Received: 22 April 2021 / Accepted: 28 August 2021 / Published online: 8 September 2021

(c) The Author(s) 2021

\begin{abstract}
Predicting formation damage in cased-hole and open-hole completion wells is of high importance. This is especially relevant when the damage is caused by reservoir drill-in fluids hence being well-bore induced. Cake filter removal has proven to be a good approach to estimate induced damage and to evaluate drill-in fluids' performance. We present an experimental methodology to evaluate filter cake removal, which could be achieved during the well's initial production. An improved experimental setup, to the ones presented in literature, has been developed to enhance data quality. A twofold approach was used for setup design, and first, it can be integrated with devices used to evaluate the static/dynamic filter-cake. Second, it can be used to simulate more realistic cases (field related) by adjusting the experiment parameters. Hence, to replicate the expected drawdown pressure as well as the corresponding flow rate of the studied reservoir. Three key indicators directly related to filter-cake removal were used as evaluators in this work. Lift-off pressure, internal and external filter cakes removal efficiency. Three reservoir fluid systems were studied, two polymer-based and one potassium carbonate. Results show that pressure required to initiate the collapsing process of the filter cake is not significant. Polymer-based drilling fluids showed better performance in terms of external and internal filter cake cleaning efficiency comparing to potassium carbonate. Moreover, we observed that filtrate volume has no clear relation with the degree of residual damage.
\end{abstract}

Keywords Formation damage $\cdot$ Reservoir drill-in fluids $\cdot$ Lift-off pressure $\cdot$ Filter cakes $\cdot$ Removability

\section{Introduction}

Improper design of drilling fluids can lead to potential damage of the reservoir productivity due to different mechanisms. For instance, damage caused by plugging of the pores in the formation and creating internal filter cake. According to van Zanten et al. (2011), mechanisms include chemical incompatibility causing emulsion blockage, clay swelling and rock's wettability changes. Nevertheless, the degree of the damage caused can vary depending on different parameters. Mandal et al. (2006) refer to invasion depth of the drilling fluid and wettability changes. Xin et al. (2019) point to rock's mineral composition and their sensitivity to filtration rate, drilling fluid makeup water salinity/alkalinity. Lin

Asad Elmgerbi

asad.elmgerbi@unileoben.ac.at

1 Montanuniversitat, Leoben, Austria

2 OMV Exploration \& Production GmbH, Gänserndorf, Austria et al. (2020) indicate operational conditions, reservoir type (consolidated, unconsolidated, naturally fractured), and fracture width. Some authors also refer to reservoir rock physical properties and fines formation, drilling fluid solids size, concentration, and distribution (Aditama et al. 2013; Xin et al. 2021).

Mitigating possible damages can be operationally achieved only by a proper design of the drilling fluid intended to be used. Therefore, special drilling fluids known as reservoir drill-in fluids have been designed/developed over the past decade for reservoir section's drilling processes. Reservoir drill-in fluids are theoretically formulated to mitigate formation damage by minimizing filtrate loss via forming an easy-to-remove impermeable thin filter cake (Mandal et al. 2006). Nevertheless, the main challenges that may face the fluid designer during the designing phase of a reservoir drill-in fluid relate mainly to evaluating and addressing the potential formation damage caused by the used fluid for improving the design or to select the optimum reservoir drill-in fluids to drill the reservoir section with less damage. Hence, several laboratory-scale methods and tools 
were developed to measure the drilling fluid's performance by estimating the possible damages that the fluid could cause. Since this paper's primary goal falls on evaluating formation damage by assessing filter-cake removability, only relevant methods and tools will be cited in the subsequent section.

Beall et al. (1997) reported the first experimental work assessing a filter cakes removal developed by reservoir drillin fluids. The authors modified the existing high-temperature high-pressure (HTHP) filter press to evaluate different breaker systems' impact on the filter cake removability. They also report evaluations for different reservoir drill-in fluids composition at different temperatures, core permeability, and exposure time. Most importantly, they used filter cake cleaning efficiency as a key indicator for results comparison and validation. Queiroz (2002) identified the impact of several variables on the magnitude of lift-off pressure of the mud cake generated biopolymer drill-in fluid. To mimic field behaviour, developed an apparatus to measure the liftoff pressure of a filter media made by sandstone plugs. The author found that lift-off pressure value is inversely proportional with the permeability of the filter media. Moreover, reports that starch polymer concentration has a positive impact on reducing the lift-off pressure value. Also, that the medium calcium carbonate particle sizes proved to be more effective in reducing the lift-off pressure value. Besides that, the ranges of lift-off pressure values for all the conducted experiments were between 1 and 4.8 psi.

Amanullah (2003) developed a test facility to measure a filter-cake's erosion capability by defining the somewhat called "erosion coefficient". The focus was on how wellbore fluid dynamics impacts the pre-built filter-cake and indirectly linking it to formation damage. According to the author, the expected formation damage will be less when the erosion coefficient is low and vice versa. Such as finding seem to be in disagreement with the reported literature, placing some shortcomings. First, it does not mimic a realistic downhole condition in terms of pressure and temperature. Complicated procedures are involved in conducting the experiments, which can lead to a significant increase in the uncertainty of the obtained results. The approach is considered implicit, rather than explicit, since only one indicator was used to evaluate the one-sided damage of the pre-developed filter-cake.

Jin (2009) reported a methodology to study formation damage caused by a drill-in fluid due to filtration invasion using dynamic/static formation damage tester. The author used reservoir rock samples from a gas reservoir to evaluate return permeability and filter cake lift-off pressure. The experimental work revealed that water-based mud has less formation damage among the tested drill-in fluids. Moreover, found that the lift-off pressure values tend to be small. The author also points that relying on return permeability as sole indicator of formation damage is not enough. The depth of invasion must be evaluated in parallel in order to understand the damage caused. In some agreement with these findings, lift-off pressure evaluations were also presented by Han et al. (2012). The focus was on selecting the optimum reservoir drill-in fluid for an open-hole gravel pack reservoir completion. Authors report a series of experiments including filtration test at 75 bar at $80{ }^{\circ} \mathrm{C}$ prior measuring the lift-off pressure. The filtration test was performed for approximately $2 \mathrm{~h}$ using API 120 ceramic disc as filtration media. Their conclusion is in agreement with Jin (2009), and the lift-off pressure value for all the tested fluids was trivial.

Osode et al. (2014) studied the impact of 12 commercially water-based mud lubricants on base fluid properties and possible formation damage using sophisticated test facilities. The evaluations included lift-off pressure among others, showing that lubricants have a negative impact on the liftoff pressure. All examined lubricants caused an increase in lift-off pressure at different degrees, with the base fluid value around 7 psi. Lift-off pressures on that range are considered small, in particular if a real core sample is used as filter media. Moreover, $\mathrm{Li}$ and $\mathrm{He}$ (2015) conducted experimental work using Hassler cell o their evaluations. They studied the relationship between microstructures of filter cake (internal and external) with return permeability for water-based/oilbased reservoir drill-in fluids. Considering the flow initiation pressure equivalent to a lift of pressure some conclusions can be derived. Their experiments indicated that the lift of pressure is impacted by the differential pressure applied while conducting the filtration test. In other words, as the applied pressure (differential) increases, the lift of pressure becomes less.

Treating reservoir drill-in fluid formation damage by using a chemical breaker system has gained great attention in recent years. Various laboratory studies have been conducted to study the impact of different breakers systems on cleaning up the filter cakes (Mohamed et al. 2020). Mostly a combination of three methods is found on the literature for evaluating breaker effectiveness, namely breakthrough, return permeability and weighing method (Ghosh et al. 2020; Chandran et al. 2020). In addition to the mentioned conventional methods for formation damage assessment, other techniques are used to evaluate the damage differently. For instance, Rostami and Nasr-EI-Din (2010) used X-ray diffraction and scanning electron microscope to study the crystallographic structure and morphology of the external filter cakes. Elkatatny et al. (2012) reported using a CT scanner to measure the external filter cake physical properties. Vryzas et al. (2017) utilized the nuclear magnetic resonance (NMR) spectroscopic and magnetic resonance imaging (MRI) technique to evaluate the formation damage caused by the fluid invasion. 
On spite of the reported literature data proposing methods to assess formation damage and well-bore clean-up solutions. Some parameters such as time effect or correlations between removing the filter cake and its residual damage require additional studies. On one side, the time required to effectively remove the filter cake is an important parameter. On the other side, the correlation between the efficiency of removing the external filter cake and residual damage is crucial. Therefore, we focus on extending the literature body complementing previous works in terms of evaluating selfdestructing of reservoir drill-in fluids. We investigate the relationship between filtration time and lift-off pressure as the primary approach. This, to understand links between the efficiency of removing the external filter cake and the residual internal filter cake. Consequently, we have developed a customized test facility using a twofold approach for setup design. First that the setup can be integrated with devices used to evaluate the static/dynamic filter-cake. Second, it can simulate more realistic cases (field related) by adjusting the experiment parameters. The latter is to replicate the expected drawdown pressure as well as the corresponding flow rate of the studied reservoir. In that sense, we exclude investigating specific drilling fluids/reservoirs, but rather we provide meaningful data and detailed analysis.

\section{Overall approach}

The main goal of the presented experimental work is to evaluate the residual formation damage. We study the impact of formation energy on the self-destruction of the external and internal filter-cake developed by the drilling fluid while drilling without using a chemical breaker. The proposed methodology could help defining if chemical treatment is required or can be excluded. This in turn, supports project economics since chemical treatments are costly, if not well designed, can cause severe reservoir damage (Rostami et al. 2010; Jaber Al Jaberi et al. 2021).

In general, three indicators can be used to assess and cross analyse the filter-cake self-destruction. Lift-off pressure, external filter cake removal efficiency, and residual internal filter cake. Here, we attempt at understanding if formation's energy alone will be enough to reduce formation damage to an accepted level. We therefore investigate with a focus on five specific areas relate to the topic under study. First, relation between the filtration time and lift-off pressure. Further, impact of filtration time on cleaning efficiency of the external filter cake. Estimating the formation damage by evaluating the residual internal filter cake. Evaluating the relationship between the cleaning efficiency of the external filter cake and internal damage removal efficiency. Finally, assessing the influence of permeability on the selfdestruction of the external and internal filter cakes.

\section{Experimental setup}

The schematic diagram shown in Fig. 1 presents the top view of the developed test facility used in this work. Overall, it comprises six units: (1) pumping and purging, (2) disposal, (3) pressure controller, (4) test cell, (5) piping and control valves, (6) control unit. A detailed description of the six units can be found in "Appendix 1".

The test facility has two operation modes, closed and flowing, with each mode having its individuality in terms of experimental setup and gathering results. The closed mode is used to estimate lift-off pressure value; therefore, it must be applied first. In contrast, the flowing mode is mainly used to simulate the real downhole conditions. Two essential parameters must be known beforehand, the allowable flow across the filter medium and the allowable pressure differential across the filter cake. These parameters vary from one case to another, for instance to replicate the real case, two values need to be predefined: the expected drawdown pressure and the corresponding flow rate of the studied reservoir. In other words, the reservoir's productivity index must be known prior to conduct the experimental work. See "Appendix 2" for operational steps to run the tool while conducting the experimental work for the two indicated modes.

\section{Equipment and experimental procedure}

The experimental procedure was divided into five sequential stages as indicated below:

1. Filtration test to build filter cake using static high-pressure high-temperature (HPHT) cell

2. Measure the lift-off pressure using the test facility closed mode

3. Using the test facility flowing mode to prepare the filtration medium for the next steps

4. Evaluating the external filter cake cleaning efficiency by using image analysis software

5. Estimating the residual internal filter cake by utilizing CT scan

\section{HPHT filter press cell (static filtration test)}

Static HPHT filtration test is performed by standard HPHT filter press cell using ceramic discs as porous media. All experiments were conducted at $70{ }^{\circ} \mathrm{C}$ temperature and 500 psi differential pressure. Prior to commencing the filtration test, the drilling fluids were first mixed and then conditioned for $24 \mathrm{~h}$ under $70{ }^{\circ} \mathrm{C}$ using an ageing cell. Then, once the conditioning period has been passed, the sample of the conditioned drilling fluid was transferred to HPHT for the 

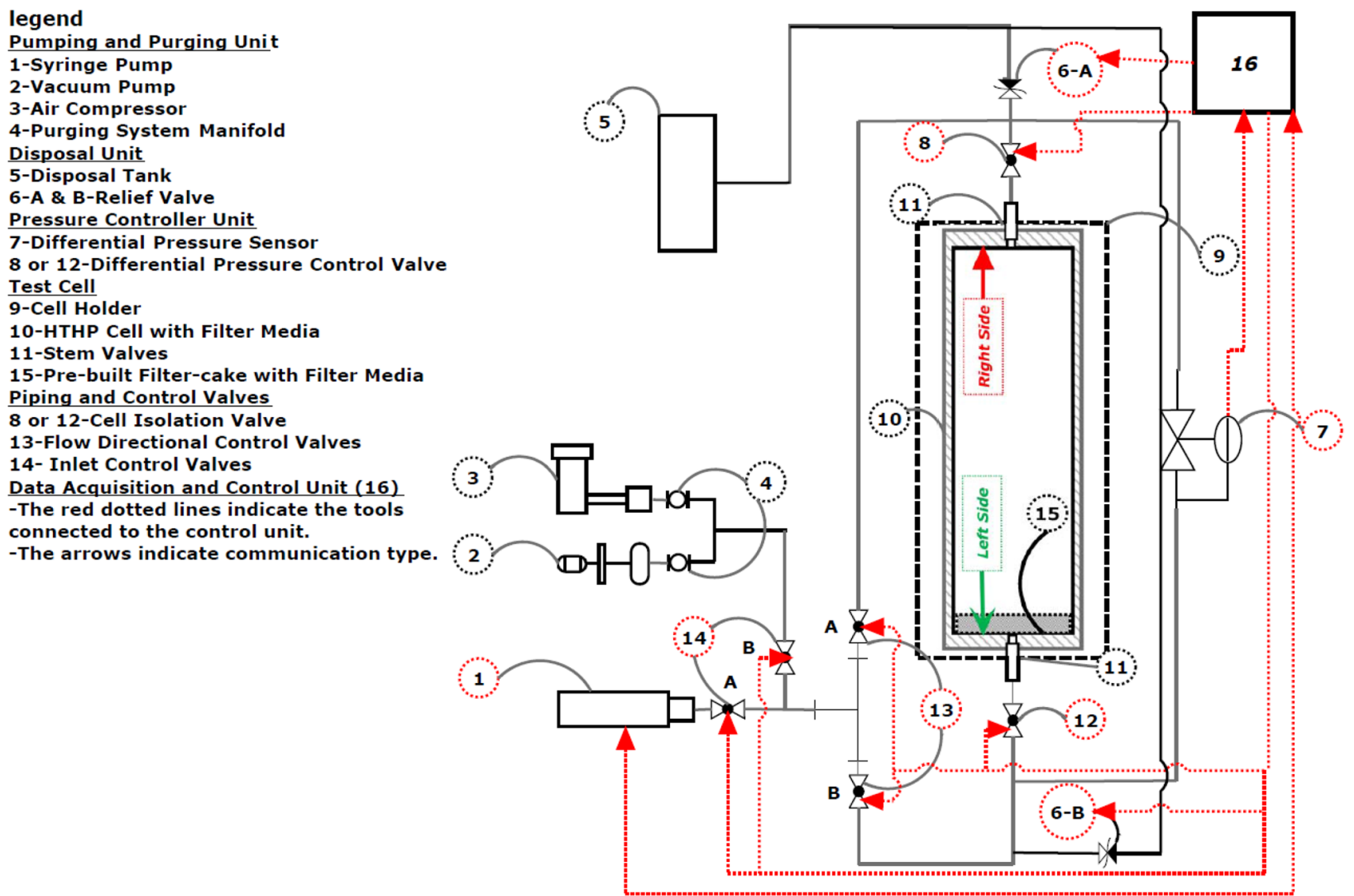

Fig. 1 Schematic representation of the test facility developed in this work. Red dotted lines indicate the parts of the test facility which the control unit can automatically operate

Table 1 Specification of the ceramic discs used for the study as porous media

\begin{tabular}{lclll}
\hline \multicolumn{2}{l}{ Mean pore throat $(\mu \mathrm{m})$} & & \multicolumn{2}{l}{ Permeability (darcy) } \\
\cline { 1 - 1 } \cline { 4 - 4 } New (mercury) & Old (air) & New (mercury) & Old (air) \\
\hline API (10) & 3 & & $775 \mathrm{mD}$ & $400 \mathrm{mD} \pm 10 \mathrm{mD}$ \\
API (20) & 10 & & $3 \mathrm{D}$ & $2 \mathrm{D} \pm 10 \mathrm{mD}$ \\
API (50) & 35 & & $15 \mathrm{D}$ & $10 \mathrm{D} \pm 10 \mathrm{mD}$ \\
\hline
\end{tabular}

filtration test. Table 1 shows the specification of the used ceramic discs (OFITE 2021).

Once the filtration period was over, the cell was opened from the top, and drilling fluid was added to the cell to avoid having an air gap at the top of the cell. This step will help to improve the results gathered while conducting the subsequent procedures.

\section{Lift-off pressure evaluation experiment}

Lift-off pressure is the initial pressure required to break down the filter cake. Hence, establishing the first communication between the fluids located upstream and downstream of the developed filter cake. In real life, it can be defined as the minimum required differential pressure between the reservoir and well-bore to initiate the collapsing process of the filter-cake and commence the flow from the reservoir to the well-bore.

Experimentally, lift-off pressure can be directly measured using the test facility (See "Appendix 1"). The maximum pressure recorded by a differential pressure sensor is the pressure at which the filter-cake starts to break down. The value of the lift-off pressure for the examined drilling fluid can be read directly while conducting the experiment by monitoring the differential pressure sensor readings. The sensor reading will increase gradually until the filter cake breaks down; at this moment, the sensor reading will decrease to zero. The differential pressure sensor's maximum recorded reading is taken as lift-off pressure for the examined drilling fluid. Figure 2 below shows the recorded differential pressure data versus time for one of the drilling fluids used for the conducted case study. Two critical parameters can be read out from Fig. 2. First is the lift-off pressure value. The second is the time taken to reach this pressure; in 


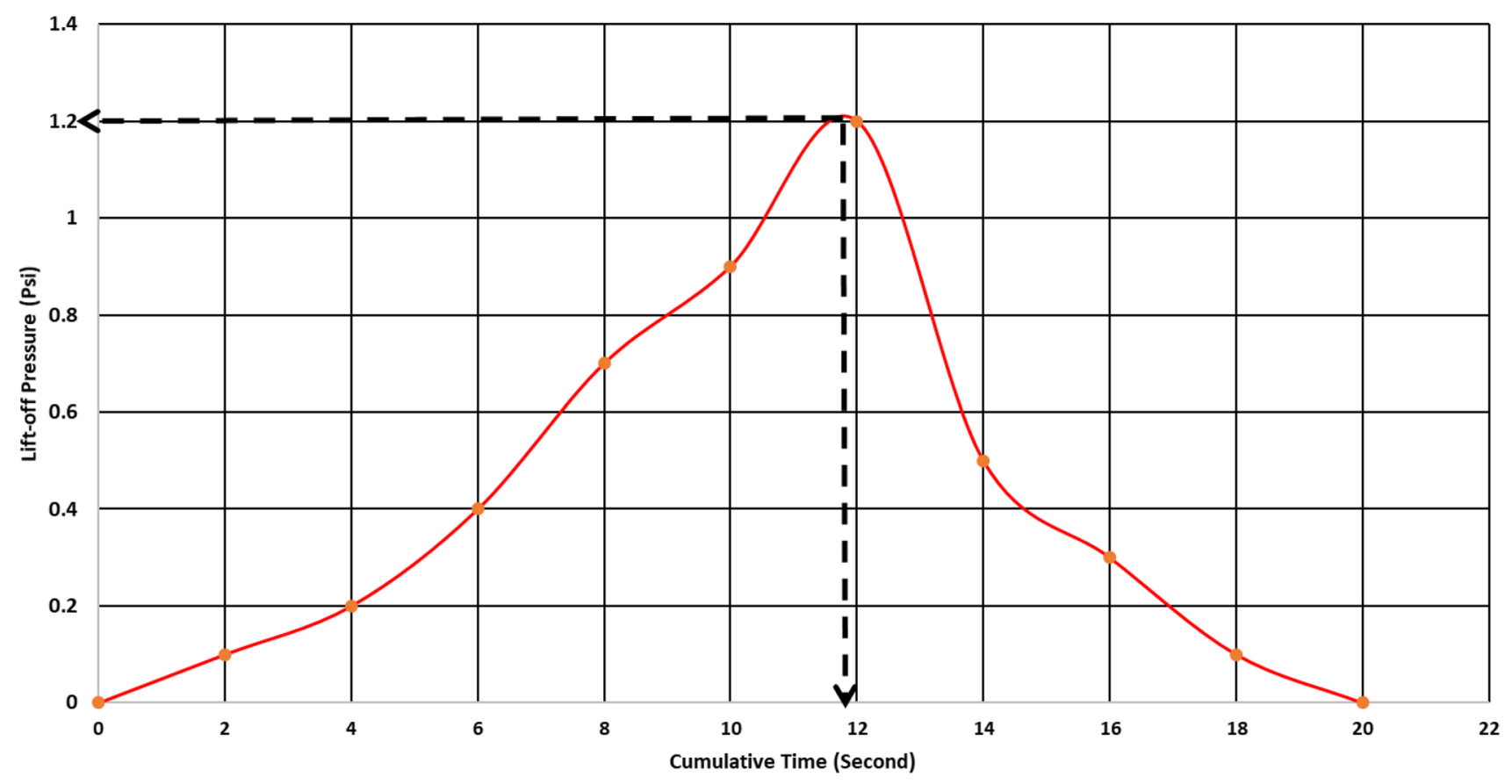

Fig. 2 An example shows how to indicate the lift-off pressure using the recorded differential pressure sensor data

this particular case, the filter-cake commenced to collapse when the backpressure reached $1.2 \mathrm{psi} ; 12 \mathrm{~s}$ was sufficient to reach the threshold collapsing pressure.

\section{Flow-back test experiment}

In this work, the flow-back test refers to applying the flowing mode procedures of the test facility. The primary purpose of this step is to mimic the case when the reservoir is put in production and allowing to flow under certain drawdown pressure. As mentioned earlier, to conduct this experiment for a specific reservoir, two values need to be predefined; these are the expected drawdown pressure and the corresponding flow rate of the studied reservoir. In other words, the reservoir's productivity index must be known prior to conduct the experimental work. For the sake of this study, brine was used as back-flow pumped crosses the filtration medium at $0.2 \mathrm{~cm}^{3} / \mathrm{min}$ flow rate under $15 \mathrm{psi}$ differential pressure for $120 \mathrm{~min}$. The value of the used back flow rate was selected to avoid being at the critical velocity (Aditama et al. 2013) as the thickness of the used filter disc is $1 / 4 "$ ", which consider as small. Applying high velocity can improve the filter cake removability; however, this case does not mimic reality. Figure 3 shows the appearances of two samples after they have been undergone the flow-back test procedures.

\section{External filter cake removal efficiency evaluating}

The removability efficiency of the external filter cake is an indirect value, which means that it cannot be read directly
Fig. 3 External filter cake appearance after $72 \mathrm{~h}$ filtration test and 120 min flow-back test

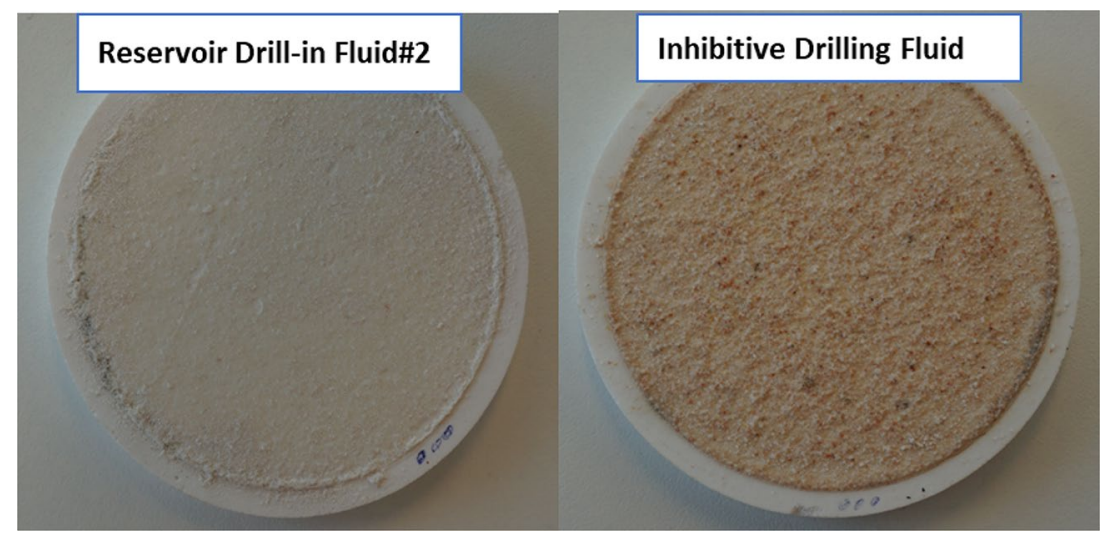


from the experiment. Therefore, to evaluate it, additional image analysis software must be used. In the presented study, we used ImageJ as the main image processing programme (ImageJ wiki). To compute the removability efficiency of the external filter cake, first, the total effective flow area (the area at which filter-cake is developed while conducting filtration test) of the filter medium must be calculated for the standard API ceramic filter disc used with $500 \mathrm{ml}$ HTHP filter press, the total effective flow area is approximately (3.9 in $^{2}$ ); however, it can be accurately determined by the image software. The second step is to define the residual external filter-cake, and based on that, the removal efficiency can be calculated by using Eq. (1):

External Filter Cake Removal Efficiency

$$
=\frac{\text { Areal of Residual External Filter Cake }}{\text { Total Effective Flow Area of the Filtration Media }}
$$

For the example shown in Fig. 4, the estimated value of external filter cake removal efficiency is $8.2 \%$, which means that $8.2 \%$ of the initially built filter-cake was removed under the applied test conditions.

\section{Residual internal filter cake evaluation}

Computed tomography (CT) scan was utilized to perform a quantitative assessment for the internal filter cake removal efficiency. Hounsfield unit value is used to identify the residual filter cake based on the density changes (Brook 1977). This technique shows its ability to accurately measure rock sample porosity and density, as indicated by Nguyen Lam and Pini (Nguyen Lam et al. 2018; Pini 2016). In this study, we followed the following steps to successfully implement the use of the Hounsfield unit to quantify the residual internal filter cake:

- The sample was scanned dry to define the Hounsfield unit value (HU), which corresponding to zero damage value (because all the porous are filled with air)

- The sample was soaked in brine for 2 days

- The sample was scanned wet to define the HU value, which corresponding to $100 \%$ damage

- After the sample was retrieved from the flow-back test, it was soaked in fresh water for two days; then, it was kept inside the oven at $25^{\circ} \mathrm{C}$ for 3 days (this step was used to ensure only solids particles remain within the pore spaces)

- The sample was scanned to define the HU, which corresponding to retained damage exerted due to the residual internal filter cake

Figure 5 presents the Hounsfield unit values for the same sample, which was scanned three times. As seen from the figure, the Hounsfield unit value is measured at multiple cross-sectional slices of the scanned disc. Since the measurement close to the edges is affected by the air, we decided to use the centerline of the disc to be the region of interest. Two substantial parameters can be derived from Hounsfield unit values, the initial porosity of the disc and the percentage of the residual internal filter cake. The initial porosity and the residual internal filter cake are computed using Eqs. 2 and 3, respectively

Initial porosity $(\emptyset)=\frac{\mathrm{HU}_{\text {Wet Sample }}-\mathrm{HU}_{\text {Dry Sample }}}{\mathrm{HU}_{\text {Dry Sample }}} \times 100$

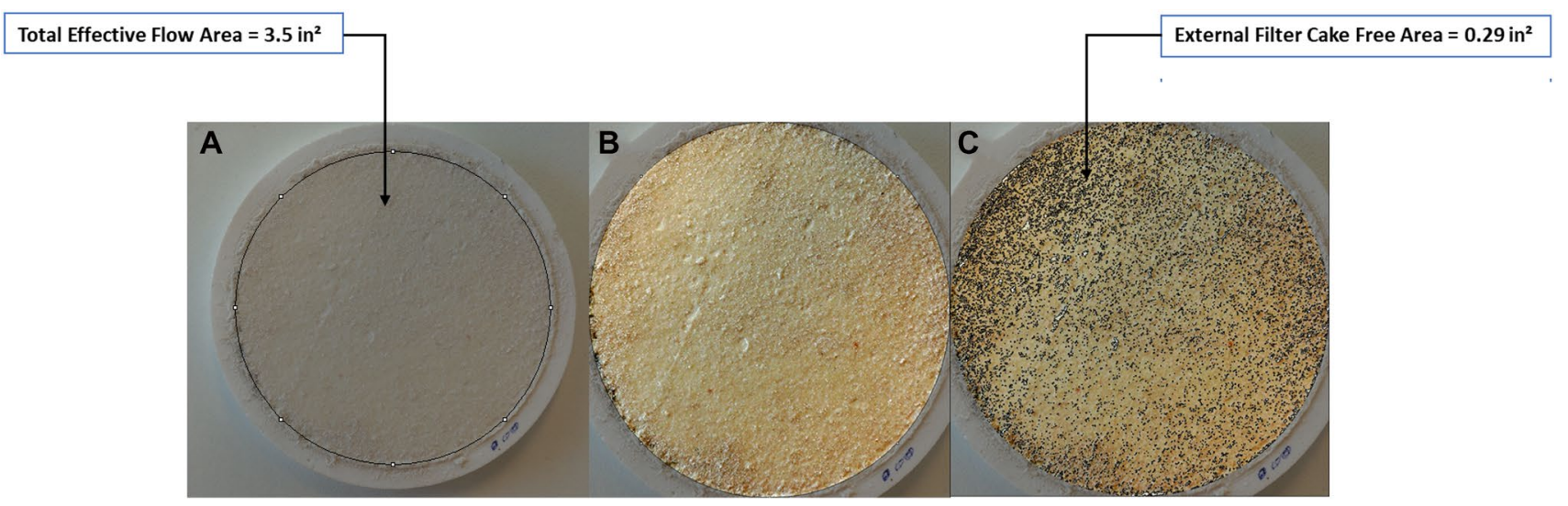

Fig. 4 Figure a shows the total effective flow area initial filter-cake was built (indicated by the black circle). b shows the residual external filter cake after applying the image enhancement process. In figure c, the black spots indicate the area in which the external filter cake was removed entirely 


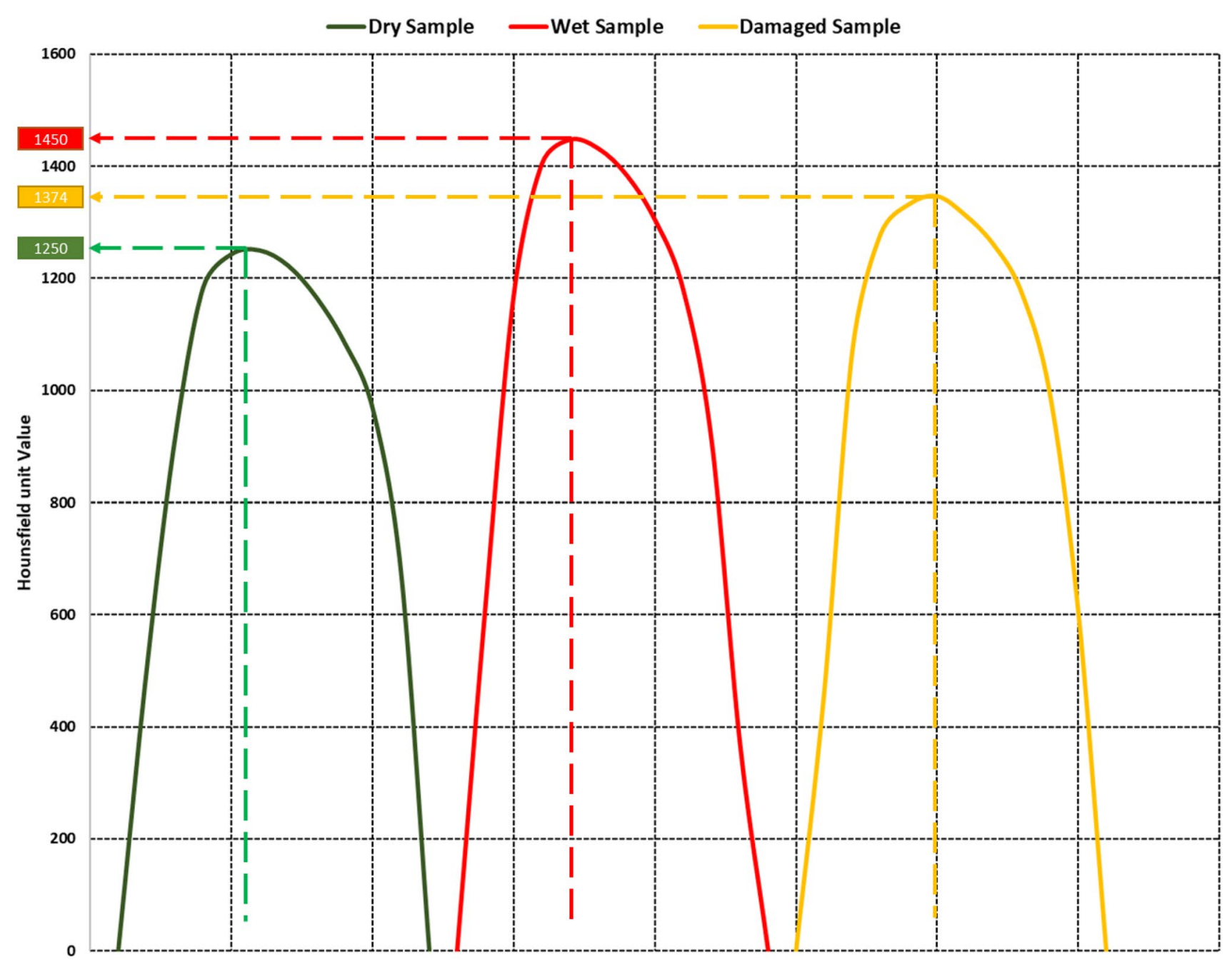

Fig. 5 Hounsfield unit values for the dry, wet, and damaged sample for the entire discs. The X-axis shows the thickness of the discs. The dotted lines indicate the centerline of the discs and the measurement points

Residual internal filter cake $(\%)=\frac{\mathrm{HU}_{\text {Damaged Sample }}-\mathrm{HU}_{\text {Dry Sample }}}{\mathrm{HU}_{\text {Wet Sample }}-\mathrm{HU}_{\text {Dry Sample }}} \times 100$

Removable effciancy of the internal filter cake(\%)

$=100-$ Residual internal filter cake

For the example shown in Fig. 5;

Initial porosity $(\varnothing)=(1450-1250) / 1250 \times 100=16 \%$
Removable effciancy of the internal filter cake $(\%)$

$=100-62=38 \%$

The value of estimated removable efficiency of the internal filter cake can be related to the initial porosity, which means $38 \%$ of $16 \%$ of initial porosity has been cleaned off; in other words, the retained porosity is $9.9 \%$.

residual internal filter cake $(\%)=(1374-1250) /(1450-1250) \times 100=62 \%$ 
Table 2 summarizes the initial porosity ranges for the three used ceramic discs.

\section{Studied drilling fluid composition and basic properties}

Three types of water-based reservoir drill-in fluids systems were used throughout the present study. Two are polymerbased and in addition to one potassium carbonate. Compositions and the basic properties of the used drilling fluids at ambient pressure are presented in Table 3.

\section{Results and discussion}

To achieve the primary goal of the research with less experimental work and gain an excellent statistical analysis of the results. We designed the experimental plan to

Table 2 Porosity ranges of ceramic discs as there were calculated by Eq. 2

Table 3 Tested fluids formulation and basic properties

\begin{tabular}{ll}
\hline Name & $\begin{array}{l}\text { Initial } \\
\text { porosity } \\
\text { range (\%) }\end{array}$ \\
\hline API (10) & $15-16$ \\
API (20) & $20-22$ \\
API (50) & $25-27$ \\
\hline
\end{tabular}

\section{Filtration time impact on lift-off pressure and external filter cake removal effectiveness}

Fifteen experiments have been conducted to evaluate the influence of filtration time on the lift-off pressure and cleaning efficiency of the external filter cake. Figure 6 shows the lift-off pressure values corresponding to filtration time for the three tested drilling fluids using API 10 disc as the filtration medium. In contrast, Fig. 7 depicts the evaluated cleaning efficiency of external filter cake for the same samples with filtration time.

Based on the results presented in Figs. 6 and 7, the following conclusions be drawn:

- The range of the pressure required to initiate the collapsing process of the filter cake of the three studied reservoir drill-in fluids systems is slightly low.

- The general model that explains the relation between liftoff pressure and filtration time is as follows:

lift - off pressure $=C+A *\left(1-e^{-k * \text { Filtration time }}\right)$

whereas: $\mathrm{C}$ is the offset from zero $\approx$ the value of liftoff pressure at 30-min test, $\mathrm{A}$ is the amplitude of the curve $\approx$ The increase in lift-off pressure values between

\begin{tabular}{|c|c|c|c|c|}
\hline Name & Additive & Concentration & Property & Value \\
\hline \multirow[t]{7}{*}{ Drilling fluid\#1 } & Water & $946 \mathrm{ml}$ & Density (ppg) & 8.8 \\
\hline & Polymer & $15 \mathrm{~g} / \mathrm{l}$ & Plastic viscosity (cp) & 14 \\
\hline & Calcium carbonate & $50 \mathrm{~g} / 1$ & Yield point (lb/100 sq.ft.) & 20 \\
\hline & Mikhart 10 & $30 \mathrm{~g} / \mathrm{l}$ & & \\
\hline & Mikhart 65 & $20 \mathrm{~g} / 1$ & & \\
\hline & Defoamer & $2 \mathrm{ml} / \mathrm{l}$ & & \\
\hline & Citric acid & $2 \mathrm{~g} / \mathrm{l}$ & & \\
\hline \multirow[t]{6}{*}{ Drilling fluid\#2 } & Water & $946 \mathrm{ml}$ & Density (ppg) & 9 \\
\hline & Polymer & $130 \mathrm{~g} / \mathrm{l}$ & Plastic viscosity (cp) & 20 \\
\hline & Potassium chloride & $31 \mathrm{~g} / 1$ & Yield point (lb/100 sq.ft.) & 38 \\
\hline & Alkalinity agent & $0.8 \mathrm{~g} / 1$ & & \\
\hline & Biopolymer & $1 \mathrm{~g} / 1$ & & \\
\hline & Modified starch & $10 \mathrm{~g} / 1$ & & \\
\hline \multirow[t]{7}{*}{ Drilling fluid\#3 } & Water & $946 \mathrm{ml}$ & Density (ppg) & 9.1 \\
\hline & potassium Carbonate & $50 \mathrm{~g} / \mathrm{l}$ & Plastic viscosity (cp) & 40 \\
\hline & Flowzan & $4 \mathrm{~g} / \mathrm{l}$ & Yield point (lb/100 sq.ft.) & 42 \\
\hline & Citric acid & $1 \mathrm{~g} / 1$ & & \\
\hline & Calcium carbonate medium & $30 \mathrm{~g} / 1$ & & \\
\hline & Calcium carbonate fine & $30 \mathrm{~g} / \mathrm{l}$ & & \\
\hline & Modified starch & $14 \mathrm{~g} / 1$ & & \\
\hline
\end{tabular}


Table 4 Experimental design matrix

\begin{tabular}{|c|c|c|c|}
\hline & Drilling fluid & Filter disc & $\begin{array}{l}\text { Filtration test } \\
\text { duration (hr) }\end{array}$ \\
\hline \multirow[t]{25}{*}{ Basic experiment } & Drilling fluid\#1 & API (10) & 0.5 \\
\hline & Drilling fluid\#1 & API (10) & 24 \\
\hline & Drilling fluid\#1 & API (10) & 48 \\
\hline & Drilling fluid\#1 & API (10) & 72 \\
\hline & Drilling fluid\#1 & API (10) & 96 \\
\hline & Drilling fluid\#2 & API (10) & 0.5 \\
\hline & Drilling fluid\#2 & API (10) & 24 \\
\hline & Drilling fluid\#2 & API (10) & 48 \\
\hline & Drilling fluid\#2 & API (10) & 72 \\
\hline & Drilling fluid\#2 & API (10) & 96 \\
\hline & Drilling fluid\#3 & API (10) & 0.5 \\
\hline & Drilling fluid\#3 & API (10) & 24 \\
\hline & Drilling fluid\#3 & API (10) & 48 \\
\hline & Drilling fluid\#3 & API (10) & 72 \\
\hline & Drilling fluid\#3 & API (10) & 96 \\
\hline & Drilling fluid\#2 & API (20) & 0.5 \\
\hline & Drilling fluid\#2 & API (20) & 24 \\
\hline & Drilling fluid\#2 & API (20) & 48 \\
\hline & Drilling fluid\#2 & API (20) & 72 \\
\hline & Drilling fluid\#3 & API (20) & 96 \\
\hline & Drilling fluid\#2 & API (50) & 0.5 \\
\hline & Drilling fluid\#2 & API (50) & 24 \\
\hline & Drilling fluid\#2 & API (50) & 48 \\
\hline & Drilling fluid\#2 & API (50) & 72 \\
\hline & Drilling fluid\#2 & API (50) & 96 \\
\hline \multirow[t]{10}{*}{ Repeated experiment } & Drilling fluid\#1 & API (10) & 0.5 \\
\hline & Drilling fluid\#1 & API (10) & 72 \\
\hline & Drilling fluid\#2 & API (10) & 0.5 \\
\hline & Drilling fluid\#2 & API (10) & 48 \\
\hline & Drilling fluid\#3 & API (10) & 24 \\
\hline & Drilling fluid\#3 & API (10) & 48 \\
\hline & Drilling fluid\#2 & API (20) & 48 \\
\hline & Drilling fluid\#2 & API (20) & 72 \\
\hline & Drilling fluid\#2 & API (50) & 0.5 \\
\hline & Drilling fluid\#2 & API (50) & 24 \\
\hline
\end{tabular}

the four days filtration test and 30-min filtration test, and $K$ is a constant.

- Lift-off pressures value increases by filtration time. Nevertheless, the increase rate is fast only at the first 2 days; beyond that, it substantially decreases. Using drilling fluid\#1 as an example, we can see that the change in liftoff pressures value between $30 \mathrm{~min}$ and 1 day, 1 day and 2 days, 2 days and 3 days, 3 days and 4 days are 2.5, 2.3, 1.2 , and 0.3 , respectively.

- External filter cake removal efficiency declines as the filtration time increases.
- As demonstrated in Fig. 7, polymer-based drilling fluids show better performance in external filter cake cleaning efficiency compared to potassium carbonate.

- In general, lift-off pressure is developing over time; however, its value is not significant to be considered as a prime indicator to evaluate formation damage, which can be demonstrated by comparing the lift-off pressure and the external filter cake removal efficiency of the potassium carbonate fluid, despite its lift-off pressures values are within the reasonable range comparative to the other two fluids, its developed external filter cake not easy to be removed when compared with them.

\section{Permeability effect on lift-off pressure and external filter cake removal effectiveness}

To understand the permeability role in reducing induced formation damage caused by reservoir drill-in fluids, 15 experiments were performed using a filtration medium with higher permeability. Figure 8 compares the lift-off pressure and external filter cake removal effectiveness for the three filtration mediums, API10, 20, and 50. The estimated permeability for the three discs is 775 Millidarcies, 3 Darcy, and 15 Darcy, respectively. The following remarks can be drawn from Fig. 8:

- The permeability effect follows the same trend observed from Figs. 6 and 7, which means, as the filtration time increases, the lift-off pressure is rising. The cleaning efficiency is reducing at the same pace.

- The removability of the external filter cake has a direct proportion to the permeability of the filter medium. As the filter medium's permeability increases, the filter cake's removability becomes more efficient, which can be noted by comparing the values of cleaning efficiency gained by API50 and 20. As it can be seen, the efficiency improved almost double.

- Time has a negligible impact on lift-off pressure for high permeable filtration medium.

\section{Residual internal damage estimation}

The results obtained from the CT scanner, as shown in Fig. 9, indicated that:

- The potential residual damage magnitude depends greatly on filtration time; in practical words, as time goes, the damage percentage enormously increases, especially for low permeable media.

- Permeability remarkably enhances the cleaning efficiency of the internal filter cake, as shown by the results obtained from using API50 as a filtration medium compared to the others. 


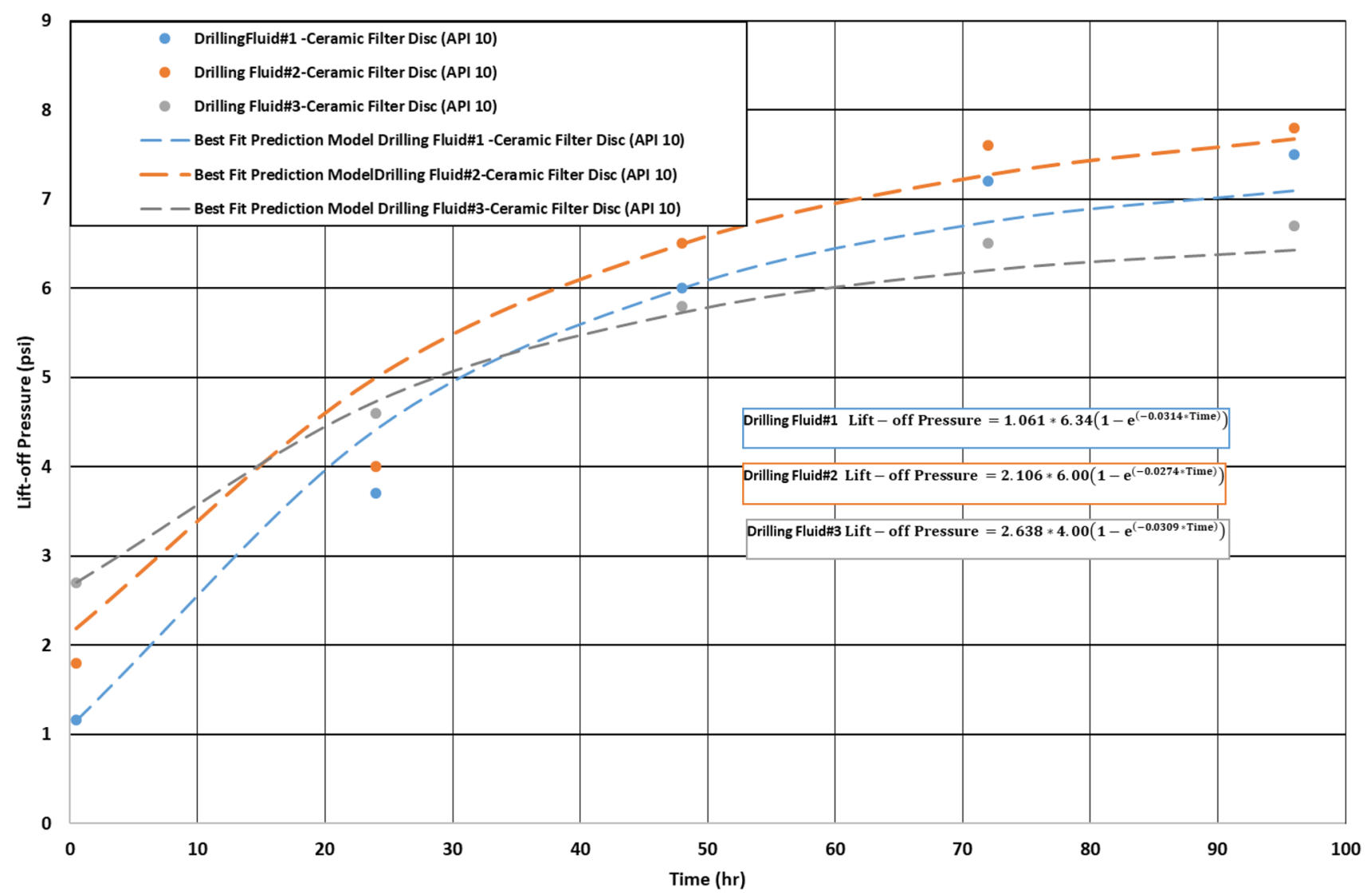

Fig. 6 The dots in the figures present the lift of pressure in the psi unit measured by the experiment; the dotted lines show the predictive value of lift of pressures, as the analytical models estimated them

- For polymer-based drilling fluids, the threshold for the decline rate of internal filter cake cleaning efficiency is $48 \mathrm{~h}$, which means, removing the internal filter cake by the formation potential becomes less efficient if the filtration time exceeds 2 days.

- The most inadequate cleaning efficiency was recorded by fluid\#3 (Potassium carbonate).

To understand the relationship between estimated internal and external filter cake cleaning efficiency, we compute the correlation coefficient between them. As shown by Fig. 10, the two variables have a strong relationship, as indicated by the correlation coefficient value $\left(R^{2}=0.972\right)$. The small error is expected because the external filter cake cleaning efficiency is subjective (depends on the person who conducts the imaging processing). Nevertheless, the error is small; therefore, evaluating the clean efficiency of the external filter cake can give a reasonable estimation of the residual damage.

\section{Additional observations}

While conducting the filtration test, the filtrate volume was measured and recorded to be used to investigate its relationship with the residual damage. We have inferred that the filtrate volume has no direct link with the degree of residual damage. Figure 11 shows explicit relation between the filtrate volume and estimated internal damage as computed by Eq. 3 . The data points highlighted by the green circle indicate the cases where the filtrate volume is high, and the corresponding damage is low; in contrast, the data points that are besieged by the red circles express the case in which the filtrate volume is low, and the resultant damage is high.

\section{Experimental error}

As reproducibility is the mirror that reflects the accuracy degree of any experimental work, we have repeated 10 experiments randomly to evaluate the experimental error. The experimental error was calculated using the following equation: 


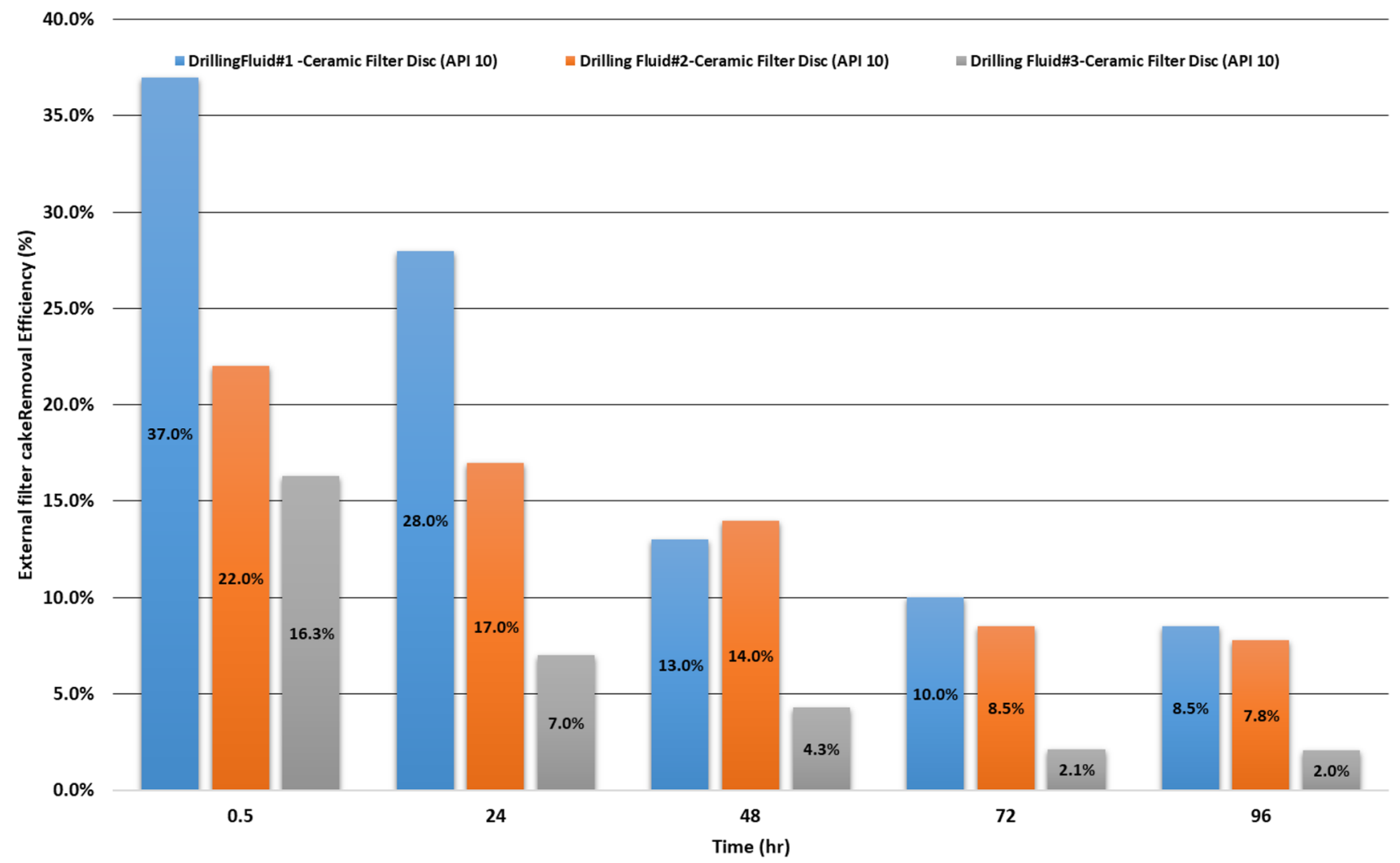

Fig. 7 External filter cake removal efficiency as a function of filtration time

experimental error $\%=\frac{\text { Actaul Value }- \text { Repeated Value }}{\text { Actaul Value }}$

where actual value presents the value obtained from the basic experiment, and repeated value is the value collected from the repeated experiment. The errors percent for the 3 factors, lift-off pressure external and internal filter cake cleaning efficiency, are illustrated as box and whisker plots in Fig. 12.

As indicated by Fig. 12, the external filter cake cleaning efficiency has the highest error, ranging between $+17 \%$ and $-23 \%$. This high error is because of the involved procedural and human, the contrary result might be concluded if different people conducted the image processing. The other 2 factors have a small because all measurement is done autonomous, with no human interference.

\section{Conclusions}

A laboratory scaled test facility was developed to quantify formation damage caused by reservoir drill-in fluid by evaluating the filter cake removal efficiency. The most outstanding feature, which the developed test facility has over the other existing tools, is exemplified in mimicking the real downhole conditions by adjusting the two influential input parameters according to the studied reservoir, namely the drawdown pressure and the corresponding flow rate. The presented methodology can be used as a potential diagnostic tool for improving the design or to select the optimum reservoir drill-in fluids to drill the reservoir section with less damage and to design the clean-up procedures.

Based on the results of the conducted experiments work, the following points can be considered as main findings:

- Lift-off pressure increases with filtration time; however, its value is not significant to be considered as prime indicator to evaluate formation damage.

- Polymer-based drilling fluids show better performance in terms of external and internal filter cake cleaning efficiency comparing to potassium carbonate.

- External and internal filter cake removal efficiency declines as the filtration time increases

- The removability of the filter cake has a direct proportion to the permeability of the filter media, whereas lift-off pressure has an inverse relation.

- A significant reduction in the filter cake cleaning efficiency behind 2 days of filtration indicates that the fil-

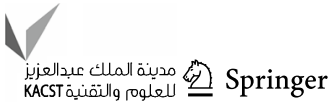




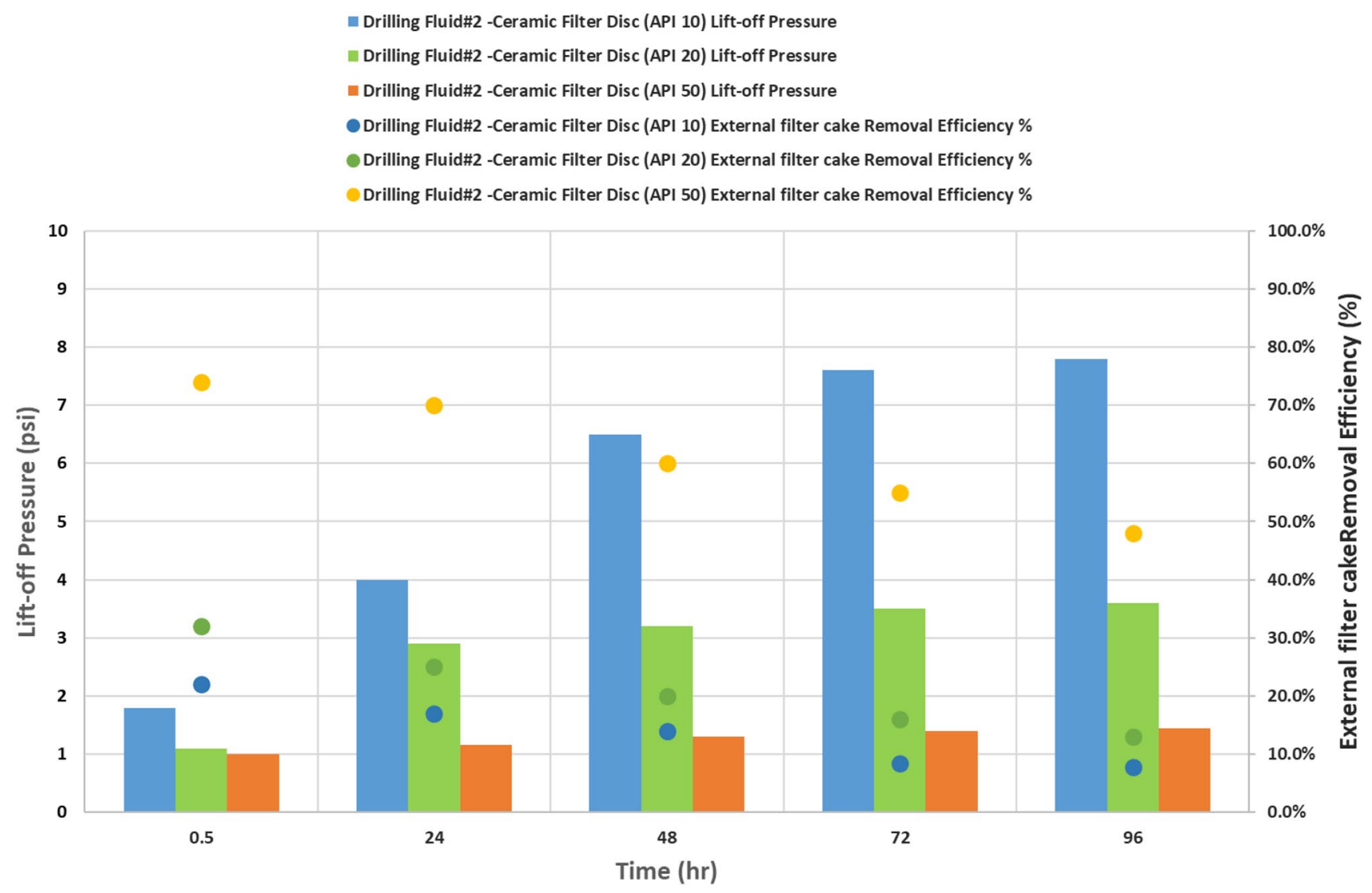

Fig. 8 Lift-off pressure and external filter cake cleaning efficiency evolution as filtration time and permeability changes of the drilling fluid\#2

ter-cake destruction by the formation energy becomes improbable.

- Filtrate volume does not reflect the drilling fluid-induced damage. Therefore, it should not be considered as a damage evaluator.

\section{Appendix 1}

\section{Pumping and purging unit}

This unit comprises:

(a) An automatic single cell volume/pressure syringe pump (1) can be used for normal and high-pressure conditions. It can measure high-precision volume and pressure for different testing media like water, oil, or synthetic fluid. The pump's primary purpose for this experiment is to simulate reservoir productivity in terms of production rate and pressure drawdown for a producer well and injection rate and pressure for an injector well. (b) Vacuum pump (2) is used for emptying the system from excess air to allow the entire system to be filled in by the drilling fluid and avoiding air pockets within the system before conducting the experiment.

(c) Air compressor (3) to purge the residual drilling fluids system once the experiment is completed.

\section{Disposal unit}

The relief valves (6) are two-way valves, have two positions, closed and open, and are connected directly to the disposal tank. Only one of the valves must be in use per experiment; the selection of the used valve mainly depends on the position of the high-temperature high-pressure (HTHP) filter press cell when it is transferred to the cell holder. For the setup shown in Fig. 1, the top relief valve is utilized, while the down one must be in closed mode all the time. The used valve must be in a closed position while conducting the first experimental procedures. Otherwise, the valve is kept in the open position, allowing the excessive drilling fluid's diversion to the disposal tank. 


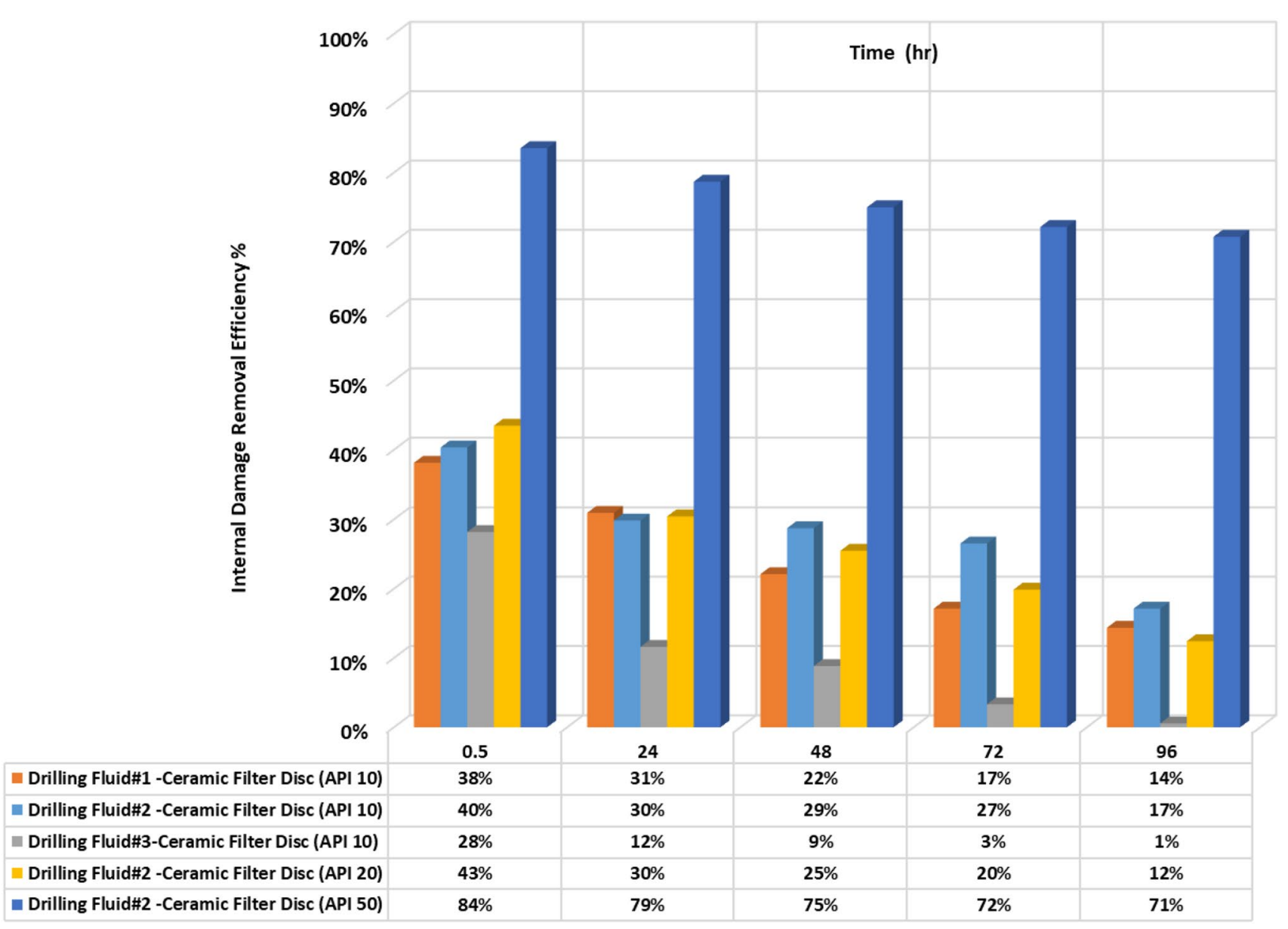

Fig. 9 Internal filter cake removal efficiency for all samples as estimated by CT scanner

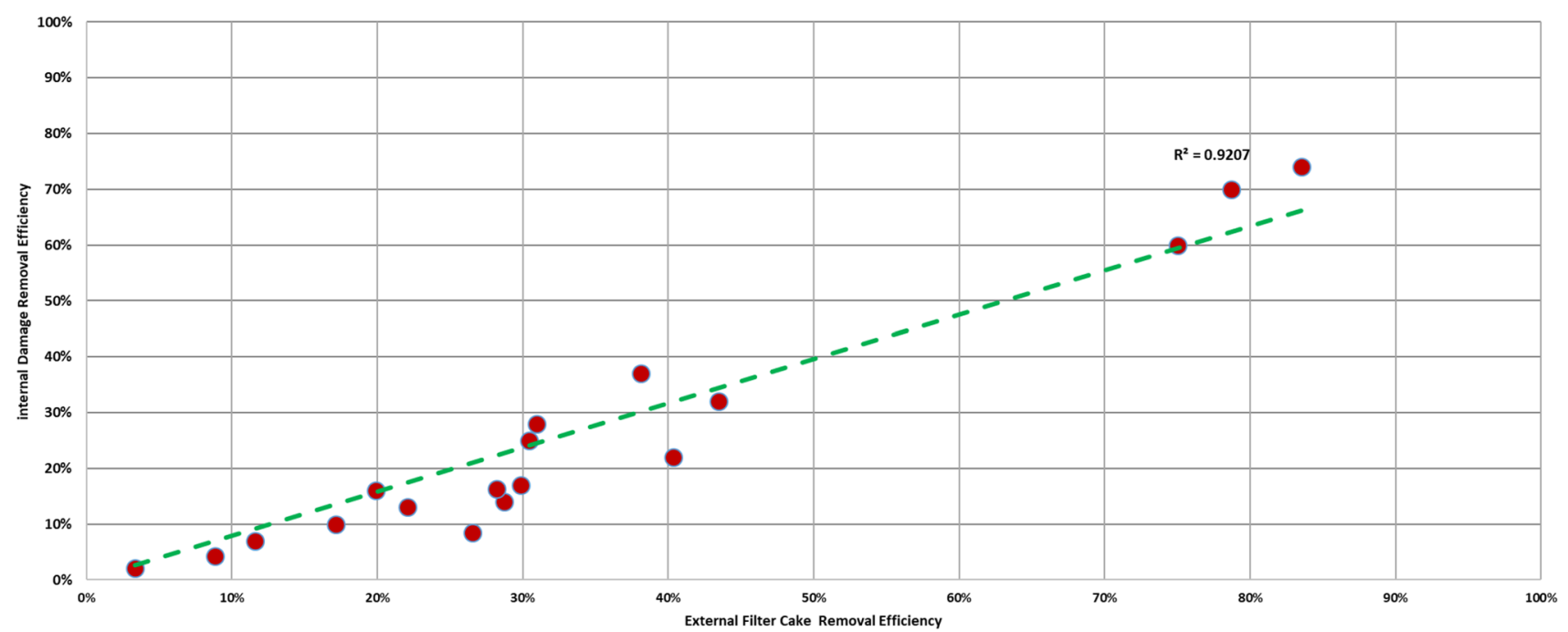

Fig. 10 Correlation between the estimated internal and external filter cakes removal efficiency for the whole studied samples 


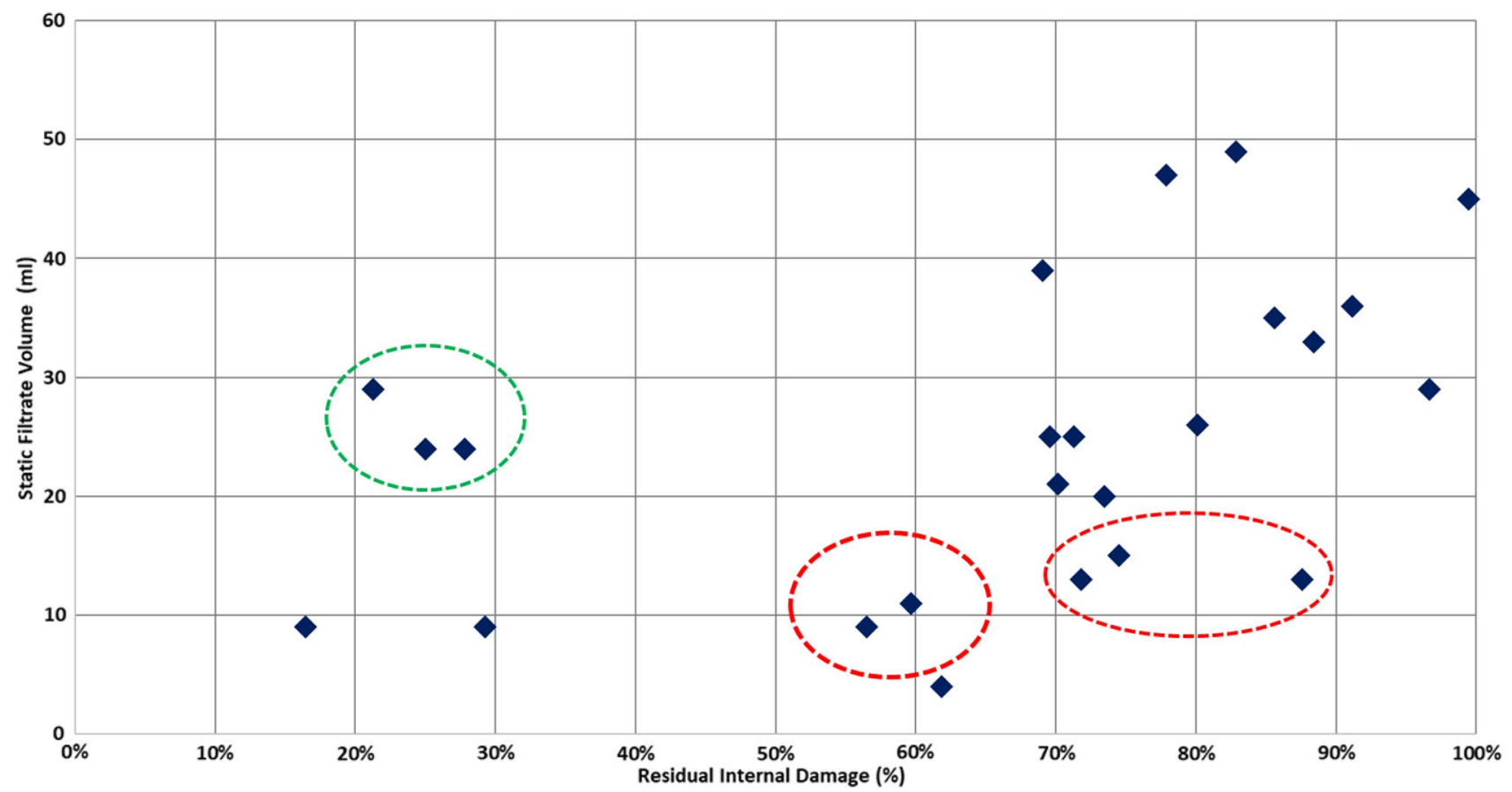

Fig. 11 Internal residual damage versus measured cumulative filtrate volume

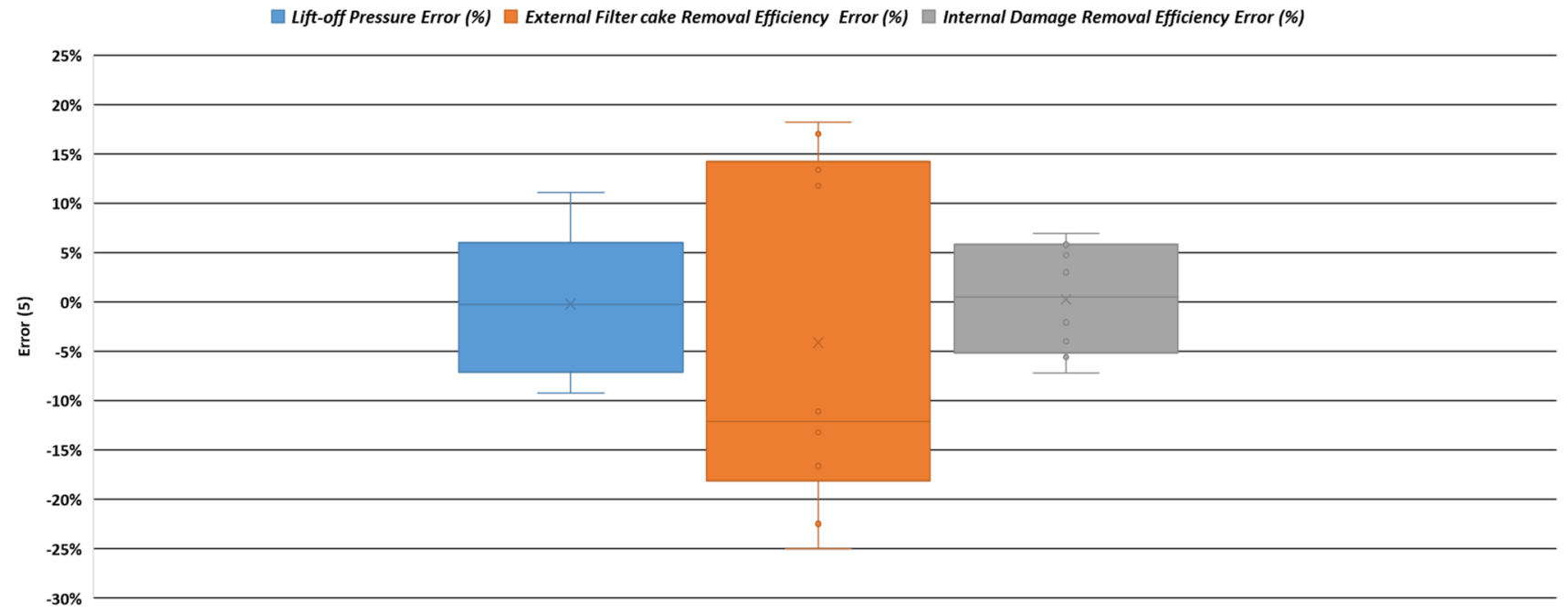

Fig. 12 Experimental error percentage for the three factors as evaluated by Eq. 6

\section{Pressure control unit}

A differential pressure sensor (7) is an essential part of the testing facility. It is integrated into the system to measure and record the initial pressure required to breakdown the filter cake while conducting the closed mode experiment and further to be used as a pressure monitor to control the differential pressure across the cell together with a differential pressure control valve ( 8 or 12) simultaneously while performing flowing mode. 


\section{Test cell}

The cell holder (9) and the stem valves (11) are designed to facilitate the connection of any commercial high-pressure high-temperature (HPHT) filter press cell (10). The HPHT cell, with the pre-built filter-cake (15), is first placed inside the cell holder, and then, it is connected to the system via the modified upper and lower stem valves. Based on the place of the filter-cake, the role of the stem valves is changing. If the (HPHT) filter press cell is positioned that the filter-cake is placed at left side as shown in Fig. 2, the lower stem valve will work as the injection port and the top stem valve as the exit port and vice versa if the filter cake is placed at the top.

\section{Piping and control valves}

The system consists of five control valves:

(a) Cell isolation valve and differential pressure control valve ( 8 or 12): The role of these two valves changes based on the position of the filter-cakes; if the filtercake placed in the left side, valve 12 works as an isolation valve and must be kept in $100 \%$ close position to isolate the cell while purging the system prior to conducting the experiment, whereas valve 8 will work as a differential pressure controller to control the pressure across the cell while conducting the filter cake removability experimental procedures.

(b) Two inlet control valves (14) are mainly used to change the system's inlet between the pumping and purging units.

(c) Two flow directional control valves (13): These valves are used to control the flow direction. When the system is in purging or cleaning mode, the two valves will be open to allow the action to be applied to the whole system. In contrast, only one of the valves will be open position while conducting the experiment based on the HPHT cell position when transferred to the test facility.

\section{Data acquisition and control unit}

As shown in Fig. 1, most of the integrated tools are connected to the control unit and can be remotely operated. All data are transfer directly to the unit and stored as text files for future analysis.

\section{Appendix 2}

\section{Closed mode}

1. After preparing a filter cake using API filtration apparatus and procedure, transfer the cell to filter cake test facility.
2. While operating the vacuum pump, valves number 6 , 8,12 , and 14-A are kept close.

3. Once the system is in a vacuum condition, close valve 14-B and open 14-A.

4. Startup the pump with a low flow rate to fill up the system with the desired back-flow fluid.

5. Continue filling up the system till the pressure across the cell is equalized; it can be identified by continuously monitoring the reading of the differential pressure sensor (nil reading means the system is in equalization status), switch off the pump.

6. Close valve 13-A (if the pre-built filter-cake is positioned in the left side as indicated in Fig. 1) and open valve 12 and 8 sequentially. If the pre-built filter-cake is positioned at the right side, close valve $13-\mathrm{B}$, then open valve 12 and 8 sequentially.

7. Resume pumping with a predefined low flow rate.

8. While pumping, keep monitoring the differential pressure sensor reading; the pressure will gradually increase until it reaches the filter cake's initial collapse pressure, then it will start slowly to decrease till it goes back to zero.

9. Once the differential pressure sensor reading indicates zero value, switch off the pump.

10. The maximum reading of the recorded differential pressure sensor is taken as a lift-off pressure.

\section{Flowing mode (flow-back test)}

1. Upon completion of the first experimental phase, open valve 6 -A and switch over valve 8 to the remote control mode (If the pre-built filter-cake is positioned at the right side open valve 6-B and switch valve 12 to the remote control mode).

2. Remote control mode is used to adjust the opening and closing of valve 8 or 12 based on the differential pressure sensor's live reading. The required differential pressure across the cell must be predefined before commencing the experiment. The applied differential pressure across the cell simulates the reservoir drawdown pressure.

3. Open valve $\mathrm{A}$ and close valve $\mathrm{B}$, start pumping with a very low flow rate $(0.05 \mathrm{ml} / \mathrm{min})$ while pumping observe the differential pressure sensor reading, when the reading reaches the predefined differential pressure (the value will be with-sign), close valve $A$, and open valve B.

4. Kick of the pump with very low flow rate $(0.05 \mathrm{ml} / \mathrm{min})$ while valve 12 is in closed position, keep pumping till differential pressure sensor reading gets back to predefined differential pressure value (the reading will be + ), then open valve 12 . 
5. Start pumping with a predefined flow rate (flow rate, which corresponds to the predefined reservoir drawdown pressure); continue pumping for the desired duration.

6. As soon as the predefined duration transcended, switch off the pump and fully open valve 8 or 12 .

7. Disconnect the cell and retrieve the filtration media with the remaining filter-cake for further analysis.

\begin{abstract}
Acknowledgements This material has not been published in whole or in part elsewhere. The manuscript is not currently being considered for publication in another journal. All authors have been personally and actively involved in substantive work leading to the manuscript, and will hold themselves jointly and individually responsible for its content.
\end{abstract}

Funding I testify on behalf of all co-authors that the authors received no specific grant from any funding agency in the public, commercial, or not-for-profit sectors for the article indicated by the title "Experimental Approach for Assessing Filter-cake Removability Derived from Reservoir Drill-in Fluids.

\section{Declarations}

Conflict of interest There is no conflict of interest.

Ethical approval I testify on behalf of all co-authors that our article submitted to Journal of Petroleum Exploration and Production Technology.

Open Access This article is licensed under a Creative Commons Attribution 4.0 International License, which permits use, sharing, adaptation, distribution and reproduction in any medium or format, as long as you give appropriate credit to the original author(s) and the source, provide a link to the Creative Commons licence, and indicate if changes were made. The images or other third party material in this article are included in the article's Creative Commons licence, unless indicated otherwise in a credit line to the material. If material is not included in the article's Creative Commons licence and your intended use is not permitted by statutory regulation or exceeds the permitted use, you will need to obtain permission directly from the copyright holder. To view a copy of this licence, visit http://creativecommons.org/licenses/by/4.0/.

\section{References}

Aditama P, Mirza M, Iswachyono T, Anwar Z, Al Saadi H, Al Kalbani M, Qassabi A, Al Raqmi M (2013) Laboratory testing approach to evaluate drill-in-fluid damage and wellbore cleanup effectivity in open hole horizontal producer wells. In: Paper presented at the SPE Asia pacific oil and gas conference and exhibition, Jakarta, Indonesia, https://doi.org/10.2118/166672-MS

Amanullah M (2003) A novel method of assessment of spurt and filtrate related formation damage potential of drilling and drilling-in fluids. In: Paper presented at the SPE Asia pacific oil and gas conference and exhibition, Jakarta, Indonesia, https://doi.org/10. 2118/80484-MS

Beall BB, Tjon-Joe-Pin R, Brannon HD (1997) Field experience validates effectiveness of drill-in fluid cleanup system. In: Paper presented at the SPE annual technical conference and exhibition, San Antonio, Texas, https://doi.org/10.2118/38570-MS
Brooks RA (1977) A quantitative theory of the Hounsfield unit and its application to dual energy scanning. J Comput Assist Tomogr 1(4):487-493. https://doi.org/10.1097/00004728-19771000000016 (PMID: 615229)

Chandran P, Kumar A, Cameron I, Jackson P, Twynam A, Reid R, Kieran S (2020) Filter cake breaker evaluation for water injectors: scale up from laboratory to field deployment. In: Paper presented at the SPE international conference and exhibition on formation damage control, Lafayette, Louisiana, USA, https://doi.org/10. 2118/199260-MS

Cuong NLQ, Minh NH, Cuong HM, Quoc PN, Van Anh NH, Van Hieu N (2018) Porosity estimation from high resolution CT scan images of rock samples by using housfield unit. Open J Geol. https://doi. org/10.4236/ojg.2018.810061

Elkatatny SM, Mahmoud MA, Nasr-El-Din HA (2012) Characterization of filter cake generated by water-based drilling fluids using CT scan. SPE Drill Compl 27:282-293. https://doi.org/10.2118/ 144098-PA

Mohamed A, Elkatatny S, Al-Majed A (2020) Removal of Calcium Carbonate Water-Based Filter Cake Using a Green Biodegradable Acid. Journal of Sustainability 12, ISSN 2071-1050, https://doi. org/10.3390/su12030994

Ghosh B, AlCheikh IM, Ghosh D, Ossisanya S, Arif M (2020) Development of hybrid drilling fluid and enzyme-acid precursor-based clean-up fluid for wells drilled with calcium carbonate-based drilling fluids. ACS Omega 5(40):25984-25992. https://doi.org/10. 1021/acsomega.0c03436.PMID:33073125;PMCID:PMC7557995

Han L, Clinch D, van der Zwaag C, Galletti E, Fornasier F, Estevez F, McMillan N, Green J, Patey I (2012) Customizing drill-in fluid for peregrino project in Brazil: laboratory development and field experience. In: Paper presented at the SPE international symposium and exhibition on formation damage control, Lafayette, Louisiana, USA. https://doi.org/10.2118/151824-MS

ImageJ wiki, https://imagej.net/

Al Jaberi J, Bageri BS, Adebayo AR, Patil S, Barri A, Salin RB (2021) Evaluation of formation damages during filter cake deposition and removal process: The effect of primary damage on secondary damage, Pet Sci. ISSN 1995-8226, https://doi.org/10.1016/j. petsci.2021.07.004.

Jin L (2009) Quantitative formation damage evaluation using dynamic/ static drill-in fluid filtration tests data. In: Paper presented at the SPE/IADC drilling conference and exhibition, Amsterdam, The Netherlands. https://doi.org/10.2118/118659-MS

Li D, and He W (2015) Journey into filter cakes: a microstructural study. In: Paper presented at the international petroleum technology conference, Doha, Qatar. https://doi.org/10.2523/ IPTC-18246-MS

Lin C, Kang Y, Xu C, You L, Zhang Z, Tan Q (2020) "An engineered formation-damage-control drill-in fluid technology for deepfractured tight-sandstone oil reservoir in Northern Tarim Basin. SPE Drill Compl 35:026-037. https://doi.org/10.2118/198915-PA

Mandal NG, Kumar UK, Kumar ABS, Gupta AK (2006) "Non damaging drilling fluid enhances bore hole quality and productivity in conventional wells of Mehsana Asset, North Cambay Basin". In: Paper presented at the SPE/IADC Indian drilling technology conference and exhibition, Mumbai, India. https://doi.org/10. 2118/102128-MS

OFITE, 2021 All rights reserved: OFI testing equipment, Inc. https:// www.ofite.com/ceramic-filter-disks

Osode P, Otaibi M, Bataweel M, Ammari S,Himes R (2014) Laboratory evaluation of formaton damage impact of drill-in fluid lubricants in a low-permeability sandstone gas reservoir. In: Paper presented at the SPE international symposium and exhibition on formation damage control, Lafayette, Louisiana, USA. https://doi. org/10.2118/168185-MS 
Pini R, Madonna C (2016) Moving across scales: a quantitative assessment of X-ray CT to measure the porosity of rocks. J Porous Mater 23:325-338. https://doi.org/10.1007/s10934-015-0085-8

Queiroz J (2002) Optimizing drill in fluid composition on filter cake lift-off pressure for openhole completion offshore applications. In: Paper presented at the international symposium and exhibition on formation damage control, Lafayette, Louisiana, https://doi.org/ 10.2118/73713-MS

Rostami, Ameneh, and Hisham Nasr-EI-Din (2010) A new technology for filter cake removal. Paper presented at the SPE russian oil and gas conference and exhibition, Moscow, Russia. https://doi.org/ 10.2118/136400-MS

Vryzas Z, Matenoglou G, Vassilios CK (2017) Assessment of formation damage potential of novel drilling fluids via integration of fluid loss data with filter cake quality and filtrate core penetration depth from NMR and MRI. In: Paper presented at the Abu Dhabi international petroleum exhibition \& conference, Abu Dhabi, UAE, https://doi.org/10.2118/188544-MS van Zanten R, Horton D, Tanche-Larsen PB (2011) "Engineering Drillin Fluids to Improve Reservoir Producibility." In: Paper presented at the SPE European formation damage conference, Noordwijk, The Netherlands, https://doi.org/10.2118/143845-MS

Zhao X, Qiu Z, Gao J, Ren X, Li J, Huang W (2021) Mechanism and effect of nanoparticles on controlling fines migration in unconsolidated sandstone formations. SPE J. https://doi.org/10.2118/ 204474-PA

Zhao X, Qiu Z, Sun B, Liu S, Xing X, Wang M (2019) Formation damage mechanisms associated with drilling and completion fluids for deepwater reservoirs. J Pet Sci Eng 173: 112-121. ISSN 0920-4105, https://doi.org/10.1016/j.petrol.2018.09.098

Publisher's Note Springer Nature remains neutral with regard to jurisdictional claims in published maps and institutional affiliations. 